Case Report

\title{
Lingual Osseous Choristoma of the Tongue Base: Unusual Presentation of a Rare Entity
}

\author{
Matthew J. Heinz, ${ }^{1}$ Scott M. Peters, ${ }^{2}$ Salvatore M. Caruana, ${ }^{3}$ and Angela J. Yoon ${ }^{2}$ \\ ${ }^{1}$ Columbia University College of Dental Medicine, New York, USA \\ ${ }^{2}$ Division of Oral and Maxillofacial Pathology, Columbia University Medical Center, New York, USA \\ ${ }^{3}$ Department of Otolaryngology, Head and Neck Surgery, Columbia University Medical Center, New York, USA
}

Correspondence should be addressed to Angela J. Yoon; ajk55@columbia.edu

Received 8 May 2017; Accepted 27 September 2017; Published 22 October 2017

Academic Editor: Abrão Rapoport

Copyright ( 2017 Matthew J. Heinz et al. This is an open access article distributed under the Creative Commons Attribution License, which permits unrestricted use, distribution, and reproduction in any medium, provided the original work is properly cited.

\begin{abstract}
Osseous lesions of the tongue, also referred to as osseous choristomas, are benign growths of bony tissue. These lesions are not true neoplasms but rather represent growth of normal tissue at an abnormal location. Clinically, they appear as exophytic masses of the tongue, and they are treated by surgical excision. Lingual osseous choristomas are rare entities, with only 71 reported cases in the literature. We present the case of a lingual osseous choristoma of the tongue base in a 21-year-old female. Of the cases of lingual osseous choristoma reported in the literature, ours is only the fifth case to involve this location.
\end{abstract}

\section{Introduction}

Osseous lesions of the tongue are an extremely rare benign entity, of which there have only been 71 documented cases [1-4]. Initially referred to as lingual osteomas, these lesions have since been reclassified as osseous choristomas [1]. This change in terminology reflects the current opinion that these are not true neoplasms but rather growths of normal tissue at an abnormal location. Lingual osseous choristomas appear clinically as exophytic masses of the tongue, and they are treated by surgical excision [1]. Herein, we present the case of a 21-year-old female with an osseous choristoma of her tongue base. Of the cases of lingual osseous choristoma reported in the literature, the tongue base has only been involved in four additional cases $[1,3-6]$.

\section{Case Presentation}

A 21-year-old female was referred to the ENT department at Columbia University Medical Center for a "bothersome" lesion of her tongue. The patient's medical history was noncontributory; however, she did report that she was a current everyday smoker. No history of intraoral trauma was reported.
Fiberoptic examination revealed a pedunculated, smooth, dome-shaped mass of the tongue base. The mass measured approximately 4 to $5 \mathrm{~mm}$ in size and was located right of the midline (Figure 1). The remainder of the tongue appeared unremarkable. Surgical excision of the lesion via carbon dioxide laser under general anesthesia was performed both for alleviation of the patient's symptoms and for histologic diagnosis. Histologic examination revealed a nodule of dense cortical lamellar bone with minimal fibrofatty marrow underlying benign-appearing stratified squamous epithelium (Figure 2). These findings were consistent with a diagnosis of lingual osseous choristoma.

At the time of writing, the patient is one month post surgical treatment. At the one-month clinical follow-up visit post surgery, the patient was symptom free and seemed to be recovering well. She will be reevaluated again at 3 months post surgery.

\section{Discussion}

Including the current case, there have only been 72 reported instances of lingual osseous choristoma [1-4]. Gorini et al. provide a comprehensive review of 67 of the previously documented cases [1]. The authors found a wide age range 


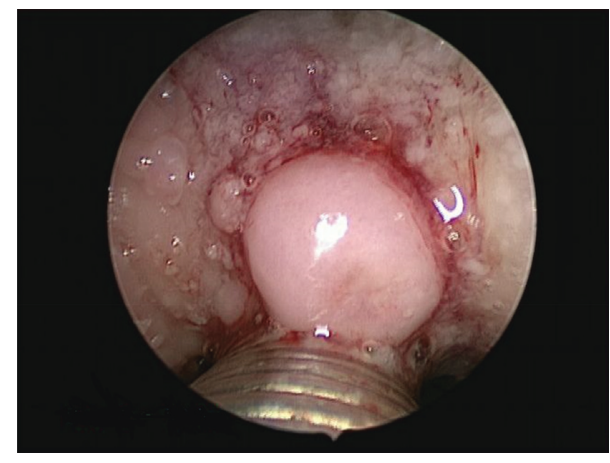

FIGURE 1: Smooth, dome-shaped mass of the tongue base identified on fiberoptic examination. The mass measured approximately $4-5 \mathrm{~mm}$ in size.

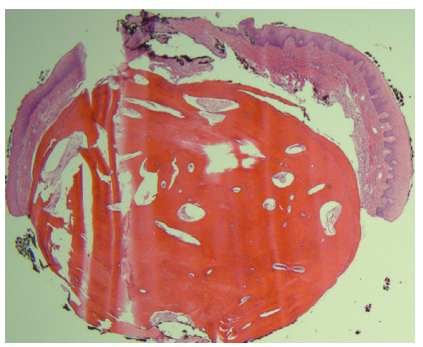

(a)

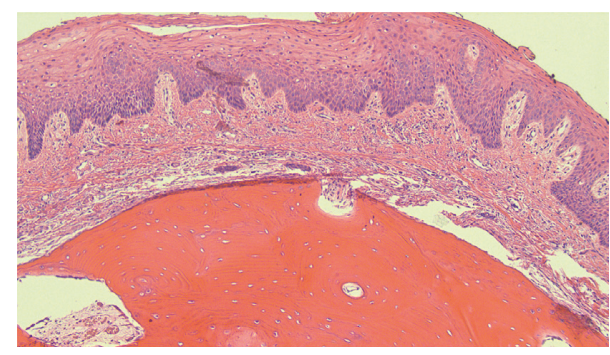

(b)

FIgURE 2: Lingual osseous choristoma. (a) Low-power photomicrograph demonstrating a nodule of dense cortical lamellar bone underlying benign-appearing stratified squamous epithelium, $H \& E \times 20$. (b) Despite its improper location within the subepithelial tissue of the tongue, the bone appears histologically unremarkable with a normal distribution of osteocytic lacunae and haversian canals, $\mathrm{H} \& \mathrm{E} \times 100$.

among the 67 cases (five to seventy-three years of age), but the majority presented during the second or third decade of life. A strong female predilection was also reported $(\mathrm{M}: \mathrm{F}$; $16: 44)$. The most frequent affected site was the posterior dorsal tongue near the circumvallate papillae [1]. Since their review in 2014, only four additional cases of lingual osseous choristoma were reported, excluding the current case [2-4]. Adhikari et al. described two cases occurring on the dorsal tongues of a 15-year-old female and a 21-year-old female [2]. Davidson et al. reported a case occurring on the tongue base in an 11-year-old male [3]. Ginat and Portugal also documented tongue base involvement in a case involving a 33year-old female [4]. Our case represents only the fifth report of lingual osseous choristoma presenting in this particular
TABLE 1: Documented cases of base of tongue osseous choristoma.

\begin{tabular}{|c|c|c|c|}
\hline Author & Age (y)/sex & Size & Symptom \\
\hline $\begin{array}{l}\text { (1) Davidson } \\
\text { et al. [3] }\end{array}$ & $11 / \mathrm{M}$ & Not reported & $\begin{array}{l}\text { "Foreign body } \\
\text { sensation" }\end{array}$ \\
\hline $\begin{array}{l}\text { (2) Ginat and } \\
\text { Portugal [4] }\end{array}$ & $33 / \mathrm{F}$ & Not reported & None \\
\hline (3) Kaye [5] & $26 / \mathrm{F}$ & $1 \times 1 \mathrm{~cm}$ & "Lump" \\
\hline $\begin{array}{l}\text { (4) Cabbabe } \\
\text { et al. [6] }\end{array}$ & $5 / \mathrm{F}$ & $\begin{array}{l}0.6 \times 0.5 \\
\times 0.3 \mathrm{~cm}\end{array}$ & "Lump" \\
\hline (5) Present case & $21 / \mathrm{F}$ & $0.5 \mathrm{~cm}$ & $\begin{array}{l}\text { "Bothersome } \\
\text { feeling" }\end{array}$ \\
\hline
\end{tabular}

$\mathrm{y}=$ years old, $\mathrm{M}=$ male, $\mathrm{F}=$ female.

location (two of the 67 cases reviewed by Gorini et al. also occurred on the base of the tongue) [1]. A complete listing of previously documented base of tongue osseous choristomas can be found in Table 1.

Lingual osseous choristomas vary in size from $3 \mathrm{~mm}$ to $5 \mathrm{~cm}$ and present clinically as hard masses that can be either pedunculated or sessile. In most cases, the covering mucosa exhibits a normal clinical appearance $[1,7]$. Lesions may be asymptomatic, but oftentimes, patients complain of choking, gagging, nausea, or dysphagia. Histologically, a well-circumscribed, lamellated mass of vital bone is seen underlying benign-appearing stratified squamous epithelium $[7,8]$.

The etiopathology of this entity is still unknown, but several theories have tried to explain its pathogenesis. Two hypotheses in particular are widely recognized. The malformation hypothesis argues that the lesion arises as undifferentiated mesenchymal cells at the line of fusion between the developing first and third branchial arches $[1,8]$. On the other hand, the traumatic hypothesis proposes that constant irritation of the tongue can lead to an osseous lesion occurring as a reactive or posttraumatic center of ossification [8].

The differential diagnosis of osseous choristoma is large and may include benign tumors of nerve or soft tissue, thyroglossal duct cyst, lingual thyroid, mucocele, pyogenic granuloma, and malignant tumors [7, 9]. However, one must consider the particular site of involvement when developing a differential diagnosis, as some of these lesions are more or less likely to present in certain areas. Surgical excision by scalpel, laser, or electronic scalpel is the most common treatment for osseous choristomas. Recurrence or malignant change has not been reported [10].

\section{Conflicts of Interest}

There are no conflicts of interest declared by any of the authors.

\section{References}

[1] E. Gorini, M. Mullace, L. Migliorini et al., "Osseous choristoma of the tongue: a review of etiopathogenesis," Case Reports in Otolaryngology, vol. 2014, Article ID 373104, 5 pages, 2014.

[2] B. R. Adhikari, J. Sato, T. Morikawa et al., "Osseous choristoma of the tongue: two case reports," Journal of Medical Case Reports, vol. 10, p. 59, 2016. 
[3] S. Davidson, M. Steiner, and M. Nowicki, "Lingual osseous choristoma," Journal of Pediatrics, vol. 168, p. 247, 2016.

[4] D. T. Ginat and L. Portugal, "Lingual osseous choristoma," Ear Nose \& Throat Journal, vol. 95, pp. 260-261, 2016.

[5] W. H. Kaye, "Osteoma of the tongue," Journal of Laryngology and Otology, vol. 82, no. 3, pp. 269-271, 1968.

[6] E. B. Cabbabe, C. Sotelo-Avila, S. T. Moloney, and M. V. Makhlouf, "Osseous choristoma of the tongue," Annals of Plastic Surgery, vol. 16, no. 2, pp. 150-152, 1986.

[7] L. S. Chou, L. S. Hansen, and T. E. Daniels, "Choristomas of the oral cavity: a review," Oral Surgery, Oral Medicine, and Oral Pathology, vol. 72, no. 5, pp. 584-593, 1991.

[8] M. H. Benamer and A. M. Elmangoush, "Lingual osseous choristoma case report and review of literature," Libyan Journal of Medicine, vol. 2, no. 1, pp. 46-48, 2007.

[9] P. Engel and H. M. Cherrick, "Extraosseous osteomas of the tongue," Journal of Oral Medicine, vol. 31, no. 4, pp. 99-103, 1976.

[10] C. L. Shao, F. S. Wan, N. Shin et al., "Lingual osteoma," Journal of Medical Science, vol. 30, no. 3, pp. 97-99, 2010. 


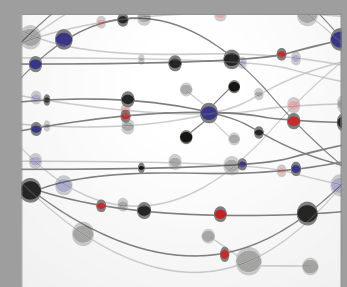

The Scientific World Journal
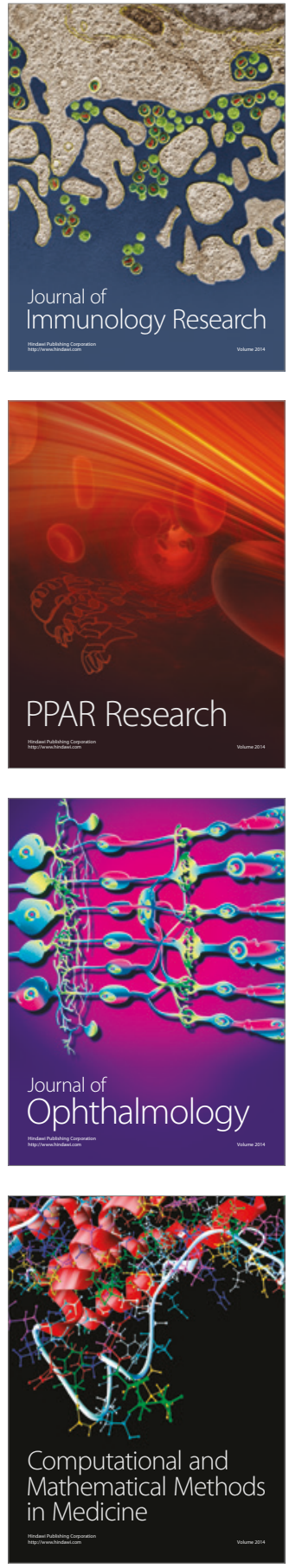

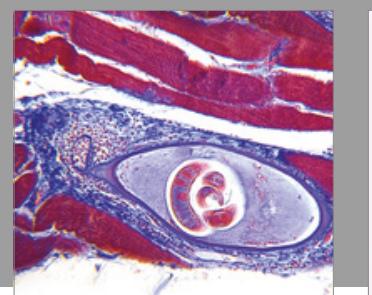

Gastroenterology Research and Practice
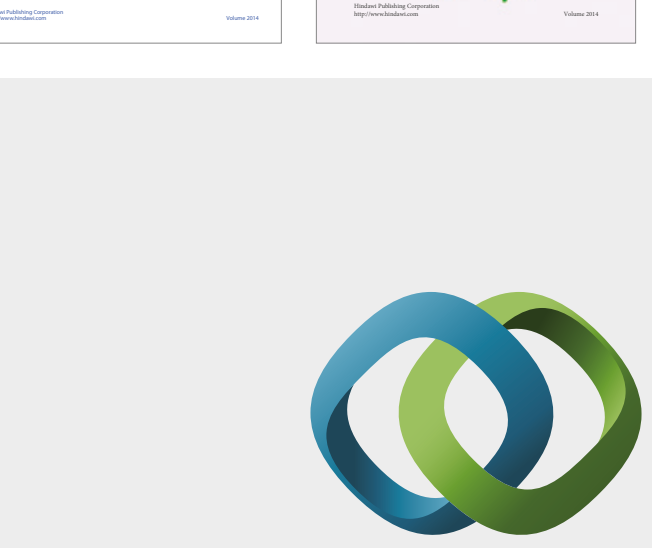

\section{Hindawi}

Submit your manuscripts at

https://www.hindawi.com
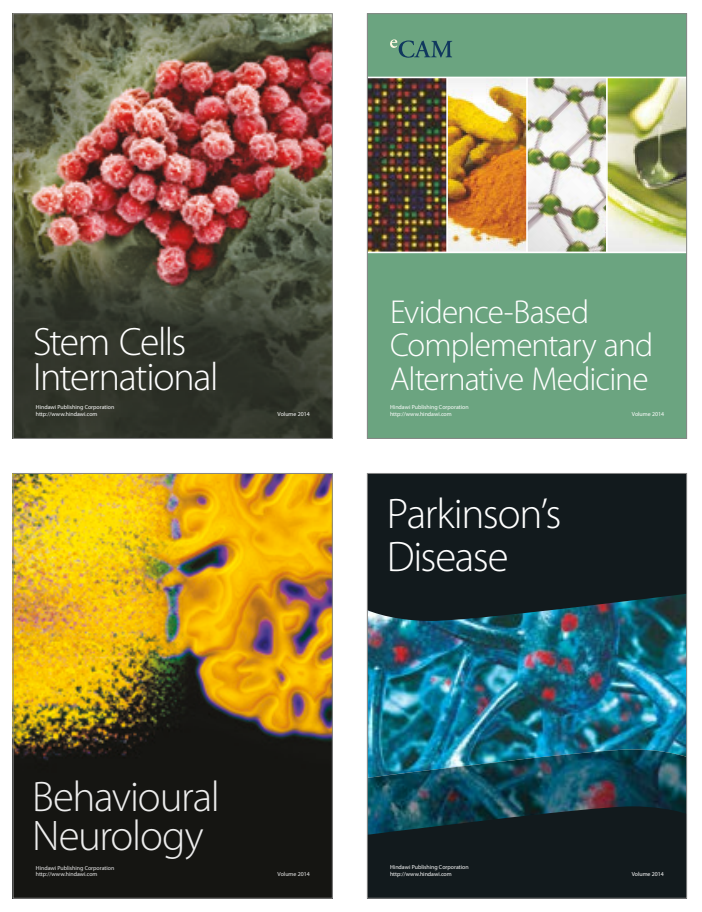
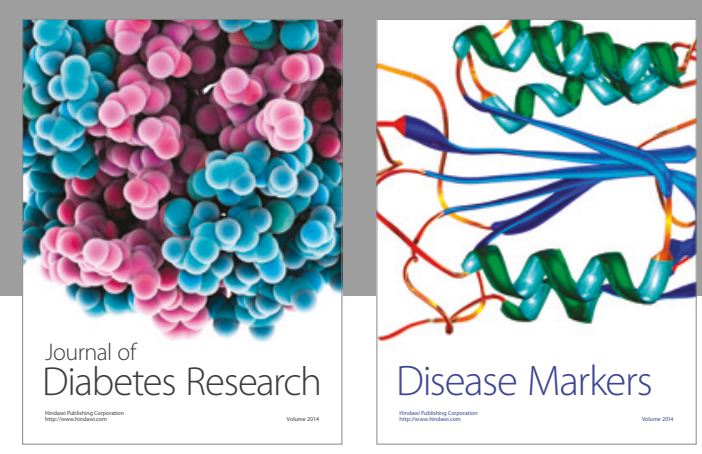

Disease Markers
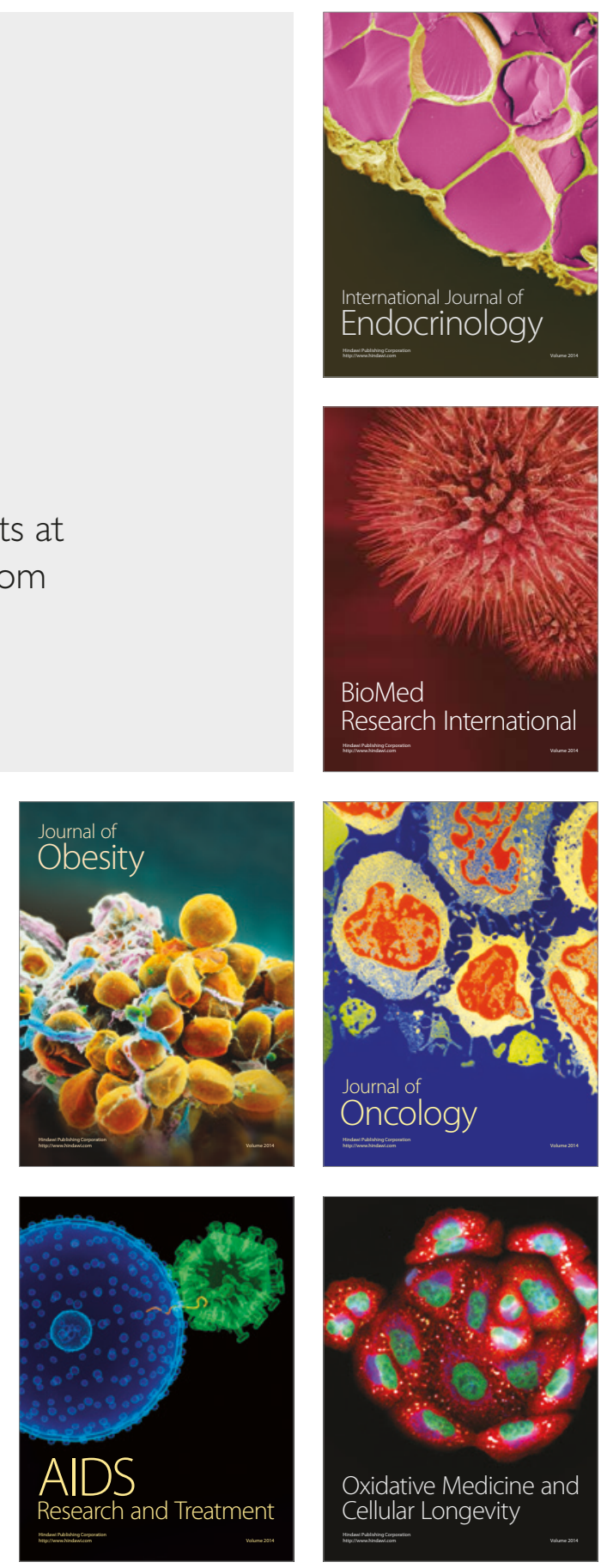